TITLE PAGE

A resource for teaching emergency care communication

Susy Macqueen $\mathrm{PhD}^{1}$, Robyn Woodward-Kron $\mathrm{PhD}^{1}$, Eleanor Flynn MBBS ${ }^{1}$, Katharine Reid $\mathrm{PhD}^{1}$, Kristine Elliott $\mathrm{PhD}^{1}$, Diana Slade $\mathrm{PhD}^{2}$

${ }^{1}$ University of Melbourne, Australia; ${ }^{2}$ University of Technology, Sydney, Australia and Hong Kong Polytechnic University ${ }^{2}$

Correspondence: Robyn Woodward-Kron PhD, Department of Medical Education,

University of Melbourne, 202 Berkeley St, Parkville Victoria, 3010, Australia. Ph. 61-383443072,robynwk@unimelb.edu.au 


\title{
A resource for teaching emergency care communication
}

\begin{abstract}
Background Communication in emergency departments (ED), which is often between several health professionals and the patients and relatives, is a major cause of patient complaint and error. However communication skills teaching for medical students largely focuses on individual clinician-patient interactions.
\end{abstract}

Context We developed and implemented an evidence informed online resource, Communication for Health in Emergency Contexts (CHEC)

http://www.chec.meu.medicine.unimelb.edu.au, to raise medical students' awareness of the challenges of communication in the ED, and to provide students with communication strategies for addressing these challenges. The foundation of the CHEC resource was the findings and data of a large research project conducted at five emergency departments in Australia from 2006-2009. From this, we developed ED scenarios and teaching vignettes using authentic communication data. The project included a nationwide medical curriculum scoping phase, involving interviews with medical students and educators, on ED communication curriculum needs in order to inform the educational activities.

Innovation The CHEC resource provides students with the opportunity to follow real-life scenarios through all stages of the ED journey, while insights from ED medical and nursing staff provide learning opportunities about interprofessional communication for medical students. Evaluation suggests that students find the resource useful and the resource has been successfully embedded in medical and junior doctor training about communication and quality and safety.

Implications The CHEC resource enhances the capacity of busy clinical educators to raise students' awareness of the communication needs of emergency healthcare by focusing on 
communication in high stress, time pressure settings using a web-format.

\section{Background}

There are unique communication challenges in emergency healthcare including limited contact time resulting in truncated interactions (1), anxious and aggressive patients (2), multitasking and multiple interruptions (3), teamwork communication (4) and multiple handovers (5). These challenges have potential to compromise patient care and safety, yet little attention is paid to specialty communication in communication skills teaching in medical curricula (6). In addition, resources used to teach health-professional patient communication tend to be semi-scripted interactions between two people (clinician and patient), resulting in exchanges that are sequential and uninterrupted by other speakers and background noise. Such resources show little of the complexity of emergency department communication.

This paper reports on how we sought to raise awareness amongst clinical educators and students about the challenges of communication in emergency departments as well as delivering an online resource to address these challenges, (http://www.chec.meu.medicine.unimelb.edu.au/resources/index.html). The project, Communication for Health in Emergency Contexts CHEC, was a collaborative project between the University of Technology, Sydney, Australia, and the University of Melbourne, Australia, conducted between 2009-2011.

\section{Context and research phase}

This section describes the activities that informed the design, content, implementation and evaluation of the resource. Authentic content for the development of the CHEC resource was provided by a research project on communication in five emergency departments in Australia 
conducted between 2006-2009 [7]. The CHEC team had access to the research project's interview transcripts with ED health professionals about communication activities and challenges, and to transcripts of patient communication with clinicians at the bedside from triage to disposition. One of the key findings relevant to the CHEC project was that the quality of the patient's care as well as how patients experience their care are negatively affected by two aspects: i) contextual complexity - this refers to the complex and fragmented nature of clinician-patient interactions in the ED, which can result in loss of information, and inadequate explanations to the patient; and ii) foregrounding of the medical over the interpersonal - when clinicians fail to build rapport with patients, patients' understanding of clinicians' management plans will be compromised [7]. We incorporated communication strategies identified in the emergency communication research project $[7, p .6]$ into CHEC to address these factors. Examples are shown in Table 1.

[Table 1]

The educational context of the project was as follows: in the first phase of the project, we undertook a national scoping of communication skills, including emergency communication skills teaching, in all Australian medical schools during 2009-2010. We developed the findings into a statement of needs, which guided the teaching and learning approach in the resource (Figure 1) [8-9]. Scoping of communication skills in nursing schools was also undertaken and is incorporated in the resource but is not reported in this paper.

[Insert Figure 1 here]

To gather evidence of the impact of CHEC on potential users of the resource, we invited medical students to participate in an evaluation of the CHEC resource. These students were in the final 12 months of their medical training and most were completing a three-week emergency rotation. We invited students to complete one section of the resource followed by 
an online survey evaluating the resource. The evaluation survey gathered students' views on whether they would use the resource again or recommend it to other students, the degree to which they believed that using the CHEC resource would benefit their communication skills, and their judgements on the usability of CHEC.

[Insert Figure 2 - Communication task]

\section{Innovation: the CHEC resource}

The teaching and learning resource we developed as a result of the above activities is a freelyavailable web-based resource which aims to provide both background information and practical examples for students, that is, primarily medical and nursing students, on the special communication demands of working in an ED. The resource is suitable for both tutorial and individual study for students at various stages of their clinical education as well as providing assessment opportunities. The resource includes reconstructions of several authentic clinicianpatient interactions in the ED environment and it is structured around four stages of the patient journey: Triage, Admission, Assessment and Management. Through engaging with patient-clinician encounters in each stage, students are exposed to ED processes, interprofessional perspectives, nurse-patient communication, doctor-patient communication, and clinician roles and communication strategies which arose from the primary research project. Figure 1 shows the commencement of Ewan's journey at Triage.

[insert Figure 1 - Ewan at Triage]

Students can perform a range of tasks, including interactive online activities, open-ended discussions and critical reflection activities. For those undertaking an ED rotation, the resource can be used both for individual and group access and there are suggestions for more substantial projects for interested students. The complex communication issues in the ED setting: intercultural communication, interruptions, time constraints, complex patients, patient 
anxiety, multiple health professionals and family members' perspectives are demonstrated in the different patient stories told through the video scenarios. The resource is accompanied by information for educators about the communication research underpinning the resource with suggestions for tutorial implementation.

In an environment which is often time poor for teaching, students can access the resource independently and then use the information they gain to assist them in their patient interactions in the ED and then discuss the issues with their tutors. An example occurs in the module covering the assessment section of Ewan's journey where the student is asked to review the different responses given by Ewan and his wife to the nurse at triage and the doctor taking a formal history. Students are then encouraged to follow a patient through their time in the ED and notice how many times the patient is asked for his or her story by different clinicians and the differences in the responses. The role of accompanying family member is also noted with the suggestion that students review the responses of family members as well as patients. Such student observations could form the basis for a thoughtful discussion on why patients and their relatives might respond differently to different clinicians. It also provides students with insights into the communication tasks of other health professionals, thus providing interprofessional learning opportunities. Figure 2 is a sample interactive task.

[Figure 2]

\section{Evaluation}

Forty-two medical students (20 male and 22 female students) participated voluntarily in the evaluation, conducted in August 2011 after completion of the project. Participating students rated the degree to which they believed the CHEC resource would help them improve in nine aspects of ED communication. There were generally high ratings across all evaluation items, 
with most students agreeing that CHEC could improve their understanding of the impact of communication on quality of patient care in ED (81.4\%), of factors impacting negatively on communication in the ED $(83.7 \%)$, as well as helping them to better understand the experience of ED from the patient's perspective (90.7\%). Student evaluation of the usability of the features of CHEC suggested that most found the material easy to understand $(92.9 \%$ agreed or agreed strongly), and the majority agreed that they felt confident using CHEC (78.6\%). Components of the resource including video segments and tasks are embedded in the communication skills modules that are part of the final year Transition to Practice term of the [name of University] medical course, which is delivered to approximately 320 students annually; in the 2014 evaluation of the communication component of the Transition to Practice term, the communication modules were rated positively. The CHEC resource is also used in communication skills training for Interns at two Victorian hospitals, in particular, as part of a quality and safety module on reducing complaints about communication in the ED. Approximately 50 interns complete this module annually. CHEC is made available for International Medical Graduate orientation training through the Post Graduate Medical Council Victoria.

\section{Implications}

Built in response to an educational need to address communication challenges in Emergency Departments, the CHEC online resource is firmly based on healthcare communication research and can be flexibly applied to a range of learning contexts. The development of this educational tool translates findings in healthcare communication research into professional practice through raising medical students' awareness of strategies for effective communication in the ED. 
While the project's firm grounding in authentic emergency department communication provides a valuable snapshot of the ED experience for students, the research focused almost exclusively on patient-clinician interactions. As a result, there is limited intra- or interprofessional communication represented in the teaching resource. This could be added to future iterations of the resource, or taken into account by other resource developers, or raised by clinical teachers with students in tutorial settings. This paper reports primarily on a medical education setting; however, the resource includes nursing communication, thus providing learning opportunities for nursing and medical students about communication in the ED by other health professionals. Therefore, the resource can be used in interprofessional education settings, providing potential for rich interprofessional exchange about emergency department interactions which may lead to positive impacts on health outcomes. 


\section{References}

1. Rhodes KV, Vieth T, He T, Miller A, Howes DS, Bailey O, et al. Resuscitating the physician-patient relationship: Emergency department communication in an academic medical center. Annals of Emergency Medicine. 2004;44(3):262-7.

2. Hobgood CD, Riviello RJ, Jouriles N, Hamilton G. Assessment of communication and interpersonal skills competencies. Academic Emergency Medicine. 2002 Nov;9(11):1257-69.

3. Coiera E, Jayasuryia R, Hardy J. Communication loads on clinical staff in the emergency department. Medical Journal of Australia. 2002;176(9):415-8.

4. Wright MC, Phillips-Bute BG, Petrusa ER, Griffin KL, Hobbs GW, Taekman JM. Assessing teamwork in medical education and practice: Relating behavioural teamwork ratings and clinical performance. Medical Teacher. 2009;31(1):30-8.

5. Ye K, Taylor D, Knott J, Dent A, MacBean C. Handover in the emergency department: Deficiencies and adverse effects. Emergency Medicine Australasia. 2007;19:433-41.

6. Silverman J. Teaching clinical communication: A mainstream activity or just a minority sport? Patient Education and Counseling. 2009;76:361-7.

7. Slade D, Manidis M, McGregor J et al. Communicating in hospital emergency departments. Final Report. University of Technology, Sydney. 2011. http://www.rilc.uts.edu.au/pdfs/EDCOM-maiin-report-interactive.pdf [Accessed 27 January 2015].

8. Slade D, Woodward-Kron R et al. CHEC: Communication for health in emergency contexts. Final report to the Australian Learning and Teaching Council (ALTC). (2011). 
http://www.ecinsw.com.au/sites/default/files/field/file/abs\%20final\%20CHEC_interac tive.pdf [Accessed 27 January 2015].

9. Woodward-Kron R, Flynn E, Macqueen S, Enright H, McColl G. The state of emergency communication skills teaching in Australian medical schools: Gaps, barriers and opportunities. Focus on Health Professional Education. 2013;14.3, pp. $55-69$. 
Table 1. Examples of communication strategies identified in primary research project, Communicating in hospital emergency departments (Adapted from 7, p. 9-10).

\begin{tabular}{|c|c|c|}
\hline $\begin{array}{l}\text { Communication } \\
\text { strategy }\end{array}$ & Description & Example \\
\hline $\begin{array}{l}\text { Spell out explicitly the } \\
\text { rationale for } \\
\text { management/treatment } \\
\text { options and decisions. }\end{array}$ & $\begin{array}{l}\text { Provide patients with clear reasons for ongoing } \\
\text { treatment or management plans. Wherever } \\
\text { appropriate, make the reasoning process } \\
\text { available to patients. Explain the sequence and } \\
\text { priority of treatments. }\end{array}$ & $\begin{array}{l}\text { 'Alright, but for now the priority is } \\
\text { treating the infection. Make sure } \\
\text { there is nothing nasty with the } \\
\text { biopsy and then we can talk } \\
\text { about how to get the waterworks } \\
\text { better in the long term.' }\end{array}$ \\
\hline $\begin{array}{l}\text { Recognise the patient's } \\
\text { perspective. }\end{array}$ & $\begin{array}{l}\text { Express a positive attitude to patients' } \\
\text { thoughts and feelings about their medical } \\
\text { conditions or their responses to treatment. }\end{array}$ & $\begin{array}{l}\text { 'No. You're not going crazy. I can } \\
\text { appreciate how uncomfortable it } \\
\text { must feel. It's not a very nice test.' }\end{array}$ \\
\hline
\end{tabular}


Figure 1. Statement of needs for emergency medicine communication skills teaching

\section{Statement of Needs and Considerations}

- Justification there is substantial justification for incorporating communication skills teaching in medical student emergency medicine training

- Opportunities interprofessional learning, simulation as a learning tool

- Barriers: some students' perspectives that communication skills teaching is unnecessary; time constraints of clinicians

- Gaps: students rarely receive feedback on their communication skills with patients which was confirmed by clinical educators; minimal communication teaching in specialty rotations

Implications: Due to concerns about time, money, staffing, course structure and resources, an emergency communication skills resource needs to...

- function independently as part of an existing course, not requiring onerous staff implementation

- be easy to integrate into the curriculum through 1) accessibility and 2) clear linking to research evidence, accreditation requirements, stakeholder concerns and graduate capabilities.

- be flexible so that it can be implemented and assessed at different stages of medical courses, building on principles of effective communication established earlier in the course. 


\section{University Library}

\section{- M M I E R R V A gateway to Melbourne's research publications}

Minerva Access is the Institutional Repository of The University of Melbourne

\section{Author/s:}

Macqueen, S;Woodward-Kron, R;Flynn, E;Reid, K;Elliott, K;Slade, D

Title:

A resource for teaching emergency care communication

Date:

2016-06-01

Citation:

Macqueen, S., Woodward-Kron, R., Flynn, E., Reid, K., Elliott, K. \& Slade, D. (2016). A resource for teaching emergency care communication. CLINICAL TEACHER, 13 (3), pp.192-196. https://doi.org/10.1111/tct.12423.

Persistent Link:

http://hdl.handle.net/11343/58556 